\title{
УРОКИ ЧЕРНОБЫЛЯ
}

\section{Л.И. Лукина, Д.В. Моисеев}

ФГАОУ ВО «Севастопольский государственный университет», РФ, г. Севастополь, ул. Университетская, 33

E-mail: dmitriymoiseev@mail.ru

В статье выполнен анализ причин аварии на Чернобыльской АЭС 26 апреля 1986 г. Авторы считают, что авария 1986 г. на 4-м энергоблоке произошла вследствие крайне маловероятного стечения обстоятельств. Развитию аварии во многом способствовали как конструкционные особенности реактора РБМК, так и грубые нарушения регламента его эксплуатации персоналом. Главный урок, извлеченный из аварии и её последствий, ликвидация которых продолжается и по сей день, заключается в необходимости внимательного отношения к вопросам безопасного использования достижений научно-технического прогресса в таких объектах критической инфраструктуры, как АЭС.

Ключевые слова: радиационная авария, Чернобыльская АЭС, реактор РБМК, радиационное загрязнение, причины аварии, последствия аварии

Поступила в редакцию: 11.05.2021. После доработки: 04.06.2021.

Введение. От катастрофы на Чернобыльской АЭС нас отделяет 35 лет. Однако ее причины и последствия и сегодня продолжают будоражить умы ученых, оставаться актуальными для участников работ по ликвидации последствий аварии и для сотен тысяч людей, проживавших на территориях, подвергшихся радиоактивному загрязнению, для миллионов пострадавших от последствий аварии. Авария с разрушением реактора и выбросом значительного количества радиоактивных веществ в окружающую среду произошла на четвертом энергоблоке Чернобыльской АЭС 26 апреля 1986 г.

В историю человечества эта авария вошла как одна из самых масштабных техногенных катастроф, приведшая к глобальному радиационному загрязнению. Территория более 200 тыс. км ${ }^{2}$ в Европе была загрязнена радиоактивным цезием. Наиболее пострадали Белоруссия, Российская федерация и Украина (табл. 1, рис. 1) [1].

Таблица 1. Территории (км²) в Европе, загрязненные чернобыльскими выпадениями в 1986 г.

\begin{tabular}{|c|c|c|c|c|}
\hline \multirow[t]{2}{*}{ Страна } & \multicolumn{4}{|c|}{ Районы с диапазоном плотности выпадений ${ }^{137} \mathrm{Cs}$, кБк/м } \\
\hline & $37-185$ & $185-555$ & $555-1480$ & $>1480$ \\
\hline Российская Федерация & 49800 & 5700 & 2100 & 300 \\
\hline Белоруссия & 29900 & 10200 & 4200 & 2200 \\
\hline Украина & 37200 & 3200 & 900 & 600 \\
\hline Швеция & 12000 & - & - & - \\
\hline Финляндия & 11500 & - & - & - \\
\hline Австрия & 8600 & - & - & - \\
\hline Норвегия & 5200 & - & - & - \\
\hline Болгария & 4800 & - & - & - \\
\hline Швейцария & 1300 & - & - & - \\
\hline Греция & 1200 & - & - & - \\
\hline Словения & 300 & - & - & - \\
\hline Италия & 300 & - & - & - \\
\hline Республика Молдова & 60 & - & - & - \\
\hline
\end{tabular}


Авария имела тяжелые социальноэкономические, медико-биологические, радиоэкологические последствия. В ликвидации последствий аварии приняли участие более 600 тыс. человек, в т.ч. 200 тыс. военных. Неимоверными героическими усилиями, ценой своего здоровья, рискуя жизнью, ликвидаторы аварии не допустили поступления радиоактивных веществ из разрушенного энергоблока в окружающую среду и распространение радиоактивного загрязнения, соорудили саркофаг из стали и бетона над аварийным реактором, дезактивировали большие территории и создали условия для нормального функционирования неповрежденных блоков и работы персонала.
С сильно загрязненных территорий пришлось переселять людей - до конца 1986 г. из 188 населенных пунктов (включая города Припять, Чернобыль) было вывезено около 116 тыс. человек, которых необходимо было обустроить на новых местах. Всего в результате аварии пострадало около 5 млн человек, 260 тыс. га земли было выведено из народнохозяйственной деятельности и превращены в Зону отчуждения. Экономический ущерб составил 118 млрд долларов (по курсу 1986 г.). В ликвидации аварии, строительстве нового города энергетиков Славутича участвовали все республики Советского Союза, а также Ленинград и Москва.

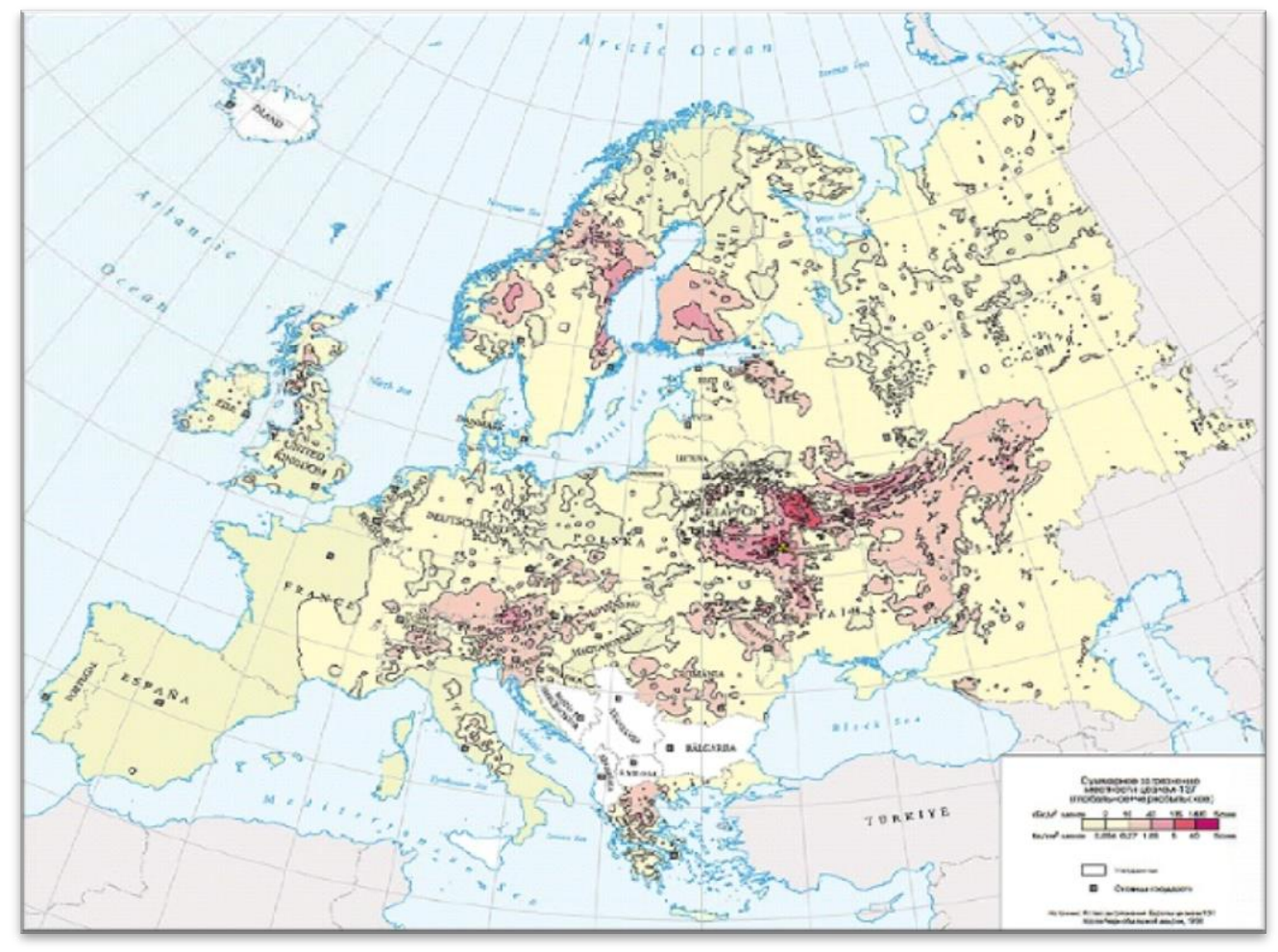

Рис. 1. Выпадения ${ }^{137} \mathrm{Cs}$ на поверхность почвы в Европе в результате чернобыльской аварии [1]

Fig. 1. Precipitation of ${ }^{137} \mathrm{Cs}$ on the soil surface in Europe as a result of the Chernobyl accident [1]

Всей отрасли атомной энергетики был нанесен большой урон, чернобыльская авария сильно ударила по её репутации. В течение шестнадцати лет после катастрофы в странах Европы и Северной Америки не было построено ни одной атомной электростанции. В России было заморожено строительство новых АЭС на 20 площадках, еще на 5 площад- ках, находившихся в высокой и средней степени готовности, все работы были остановлены [2].

Человечество в течение десятилетий постепенно отходило от шока, вызванного чернобыльской катастрофой. Но, к сожалению, техногенные катастрофы печальная реальность нашего времени. Даже самые технологически развитые 
страны не защищены от них в полной мере. Подтверждением этого явилась авария на АЭС Фукусима-1, произошедшая 11 марта 2011 г. Академик Фортов Е.Е. в предисловии к Российскому национальному докладу «30 лет чернобыльской аварии. Итоги и перспективы преодоления ее последствий в России. 1986-2016» написал: «Обе аварии, и фукусимская, и чернобыльская, по параметрам стали катастрофами общенационального масштаба, а проблемы, с которыми сталкиваются власти национального и регионального уровня при принятии решений по защите населения и территорий, требуют системных научных и междисциплинарных исследований. К новым вызовам в области обеспечения безопасности нужно отнести и вопросы противодействия террористической угрозе на объектах ядерного комплекса или с применением радиоактивных веществ. Эти вызовы требуют научного осмысления и выработки на их основе практических мер. Для создания современной, диверсифицированной, мощной и безопасной энергетики требуется, в том числе, хорошо выучить уроки прошлых тяжелых аварий и не повторять их в будущем» [3].

ЧАЭС на момент аварии. Рассмотрим, что из себя представляла ЧАЭС на момент аварии? Место её расположения - восточная часть белорусскоукраинского Полесья на берегу р. Припять, впадающей в р. Днепр. Данный регион характеризуется сравнительно плоским рельефом с небольшим количеством населения. В 30-километровой зоне вокруг ЧАЭС в начале 1986 г. проживало около 100 тыс. человек, из них 49 тыс. - непосредственно в городе энергетиков Припять, расположенном на западе от трехкилометровой санитарной защитной зоны ЧАЭС, который был признан лучшим городом страны по социально-бытовым условиям проживания. Ещё 12,5 тыс. человек проживали в г. Чернобыль, районном центре, расположенном в 15 км к югу от АЭС. Кроме того, в непосредственной близости от ЧАЭС располагались многочисленные села (рис. 2).

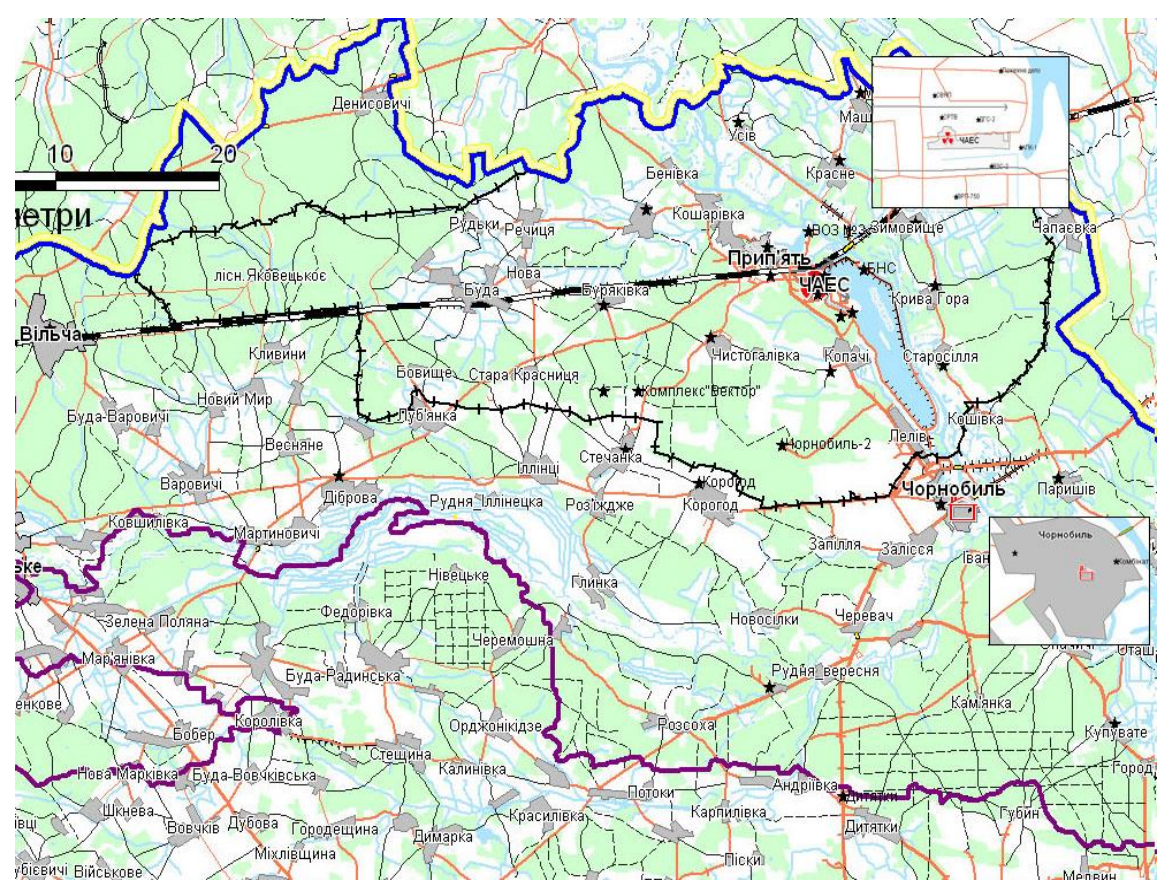

Рис. 2. Место расположения ЧАЭС

Fig. 2. Location of the Chernobyl nuclear power plant

К моменту аварии на ЧАЭС работали 4 блока, каждый из которых включал в себя ядерный реактор типа РБМК-1000 и две турбины с электрогенераторами мощностью 500 МВт. Аббревиатура РБМК расшифровывается как реактор 
большой мощности канальный, а цифра 1000 соответствует его мощности 1000 МВт или 1 ГВт. Первые два блока были сданы в эксплуатацию в 1970-1977 гг., третий и четвертый - в 1983-1984 гг. Водоснабжение АЭС осуществлялось за счет р. Припять из наливного прудаохладителя площадью 21,4 км² с замкнутой системой водоснабжения. В стадии завершения находились ещё два блока 5-й и 6-й, пуск которых планировался в декабре 1986 г. С вводом в эксплуатацию этих энергоблоков Чернобыльская АЭС должна была стать одной из самых мощных в мире.

Особенности конструкции реактора РБМК. Реактор РБМК-1000 представляет собой гетерогенный канальный реактор на тепловых нейтронах, в котором в качестве замедлителя используется графит, а теплоносителем является вода (рис. 3).

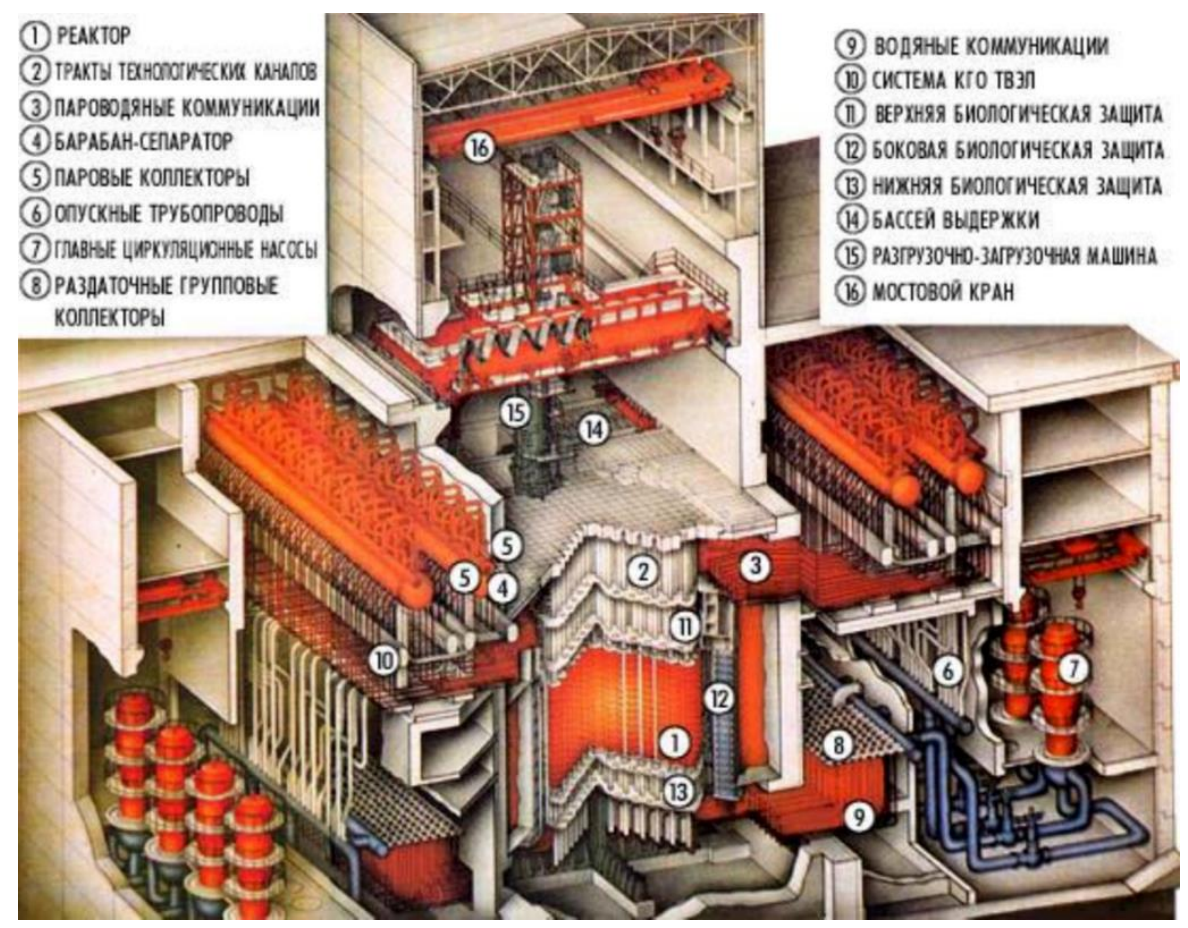

Рис. 3. Устройство реактора РБМК-1000: 1 - реактор; 2 - технологические каналы;

3 - пароводяные коммуникации; 4 - барабан-сепаратор; 5 - паровые коллекторы; 6 - опускные трубопроводы; 7 - главные циркуляционные насосы; 8 - раздаточные групповые коллекторы;

9 - водяные коммуникации; 10 - система КГО ТВЭЛ, 11 - верхняя биологическая защита;

12 - боковая биологическая защита; 13 - нижняя биологическая защита; 14 - бассейн выдержки; 15 - разгрузочно-загрузочная машина; 16 - мостовой кран

Fig. 3. The structure of the RBMK-1000 reactor: 1 - reactor; 2 - process channels; 3 - steam-water communications; 4 - drum-separator; 5 - steam collectors; 6 - lowering pipes; 7 - main circulation pumps; 8 - distribution group collectors; 9 - water communications; 10 - TVEL KGO system; 11 - upper biological protection; 12 - side biological protection; 13 - lower biological protection; 14 - holding pool;

15 - unloading and loading machine; 16 - overhead crane

В отличие от реактора ВВЭР (водоводяной энергетический реактор) в РБМК отсутствует прочный корпус. Конструкция реактора РБМК позволяет перегрузку ядерного топлива без остановки, вследствие чего увеличивается коэффициент использования мощности. Ещё одним достоинством РБМК является возможность использовать в качестве ядерного топлива (ЯТ) слабообогащенный уран, что значительно удешевляет ЯТ. В реактор загружается свыше 190 тонн ЯТ в виде тугоплавких таблеток, помещенных в ТВЭЛы (тепловыделяющие элементы), представляющие собой трубки из циркониевого сплава. Одна тонна ЯТ, состоящего из двуокиси урана $\mathrm{UO}_{2}$, основную массу которого составля- 
ет ${ }^{238} \mathrm{U}$, содержит около 20 кг ядерного горючего - ${ }^{235} \mathrm{U}$. ТВЭЛы по 18 штук объединяются в тепловыделяющие сборки, которые помещаются в вертикальные технологические каналы, размещенные в графитовой кладке, заключенной в цилиндрический корпус. Реактор расположен в наземной бетонной шахте и опирается на бетонное основание, под кото- рым находится бассейн - барботер системы локализации аварии.

В ядерном топливе происходит цепная реакция деления ${ }^{235} \mathrm{U}$ под действием тепловых нейтронов с образованием осколочных ядер и выделением большого количества тепла, нейтронов и $\gamma$ излучения:

$$
{ }^{235} \mathrm{U}+\mathrm{n}_{\mathrm{T}} \rightarrow{ }^{\mathrm{M} 1}{ }_{\mathrm{Z} 1} \mathrm{X}_{1}+{ }^{\mathrm{M} 2}{ }_{\mathrm{Z} 2} \mathrm{X}_{2}+200 \mathrm{MэB}+2,44 \mathrm{n}+7 \gamma .
$$

$\mathrm{X}_{1}$ и $\mathrm{X}_{2}$ являются продуктами ядерного деления (ПЯД) - изотопами около 200 элементов, являющимися $\beta$ - и $\beta-\gamma$ излучателями, которые, по мере выгорания ядерного топлива, накапливаются в ТВЭЛах. Часть образующихся нейтро- нов, обладающих высокой энергией, могут вступать в реакции поглощения быстрых нейтронов ядрами ${ }^{238} \mathrm{U}$ с образованием тяжелых ядер трансурановых элементов (ТУЭ) - нептуния и плутония:

$$
{ }^{238} \mathrm{U}+\mathrm{n}_{\tilde{\sigma}} \rightarrow{ }^{239} \mathrm{U} \rightarrow{ }^{239} \mathrm{~Np} \rightarrow{ }^{239} \mathrm{Pu} .
$$

ТУЭ тоже накапливаются в отработавшем ядерном топливе.

Избыток образующихся в реакции (1) нейтронов необходимо удалять во избежание цепной неуправляемой реакции ядерного распада урана. Поэтому в цилиндре реактора имеются сквозные отверстия, в которых размещаются поглотители нейтронов - стержни регулирования, изготовленные из бористой стали. В модели реактора РБМК, действующего на ЧАЭС, было 211 таких стержней регулирования количества и скорости образуемых нейтронов. По регламенту эксплуатации количество опущенных в активную зону стержней, составляющих оперативный запас реактивности, для того, чтобы способность реактора к разгону не превысила возможность поглощающих стержней заглушить реактор, должно быть не менее 28-30.

Кругооборот воды в реакторе осуществлялся шестью работающими и двумя резервными главными циркуляционными насосами.

Реактор имел также противоаварийные системы, в том числе систему управления и защиты реактора (СУЗ). Она обеспечивала пуск, автоматическое и ручное регулирование мощности, плановую и аварийную остановку реактора. Аварийная остановка осуществлялась по сигналам аварийной защиты (АЗ) или нажатием специальной кнопки А3-5.

Аварийная защита должна срабатывать при превышении заданных уровней и скорости нарастания нейтронного потока при отказах в работе оборудования, а также при превышении значений технологических параметров. По сигналу АЗ в активную зону автоматически должны быть введены стержни СУЗ, чтобы заглушить реактор.

В ядерном реакторе 4-го блока, который ко времени аварии проработал около двух с половиной лет, содержалось 190,2 тонн ядерного топлива.

Основные причины аварии на ЧАЭС. Авария произошла при проведении проектных испытаний системы обеспечения безопасности (СОБ) реактора 4-го энергоблока перед постановкой его на плановые ремонтные работы. СОБ предусматривалась для использования механической энергии вращения турбогенераторов с целью выработки электроэнергии в случае полной потери энергоснабжения АЭС, чтобы не допустить сбоя подачи воды системой аварийного охлаждения реактора, перегрев и плавление ЯТ. Поэтому испытания необходимо было проводить в режиме пониженной мощности, при которой достигается повышенный расход теплоносителя через реактор, недогрев теплоносителя 
до температуры кипения на входе в активную зону, минимальное паросодержание.

Одной из причин аварии является неверно составленная программа испытания с точки зрения безопасности. Она не была согласована с Генеральным проектировщиком (НИИ энерготехники), Главным конструктором (академик Долежаль Н.А.), научным руководителем (Институт атомной энергии им. И.В. Курчатова) и Госатомнадзором СССР.

Грубейшим нарушением программы явилось вмешательство диспетчера Киевэнерго в ход испытаний. В соответствии с программой испытаний, за сутки до аварии, 25 апреля в 01 ч 06 мин персонал 4-го энергоблока приступил к снижению мощности до 700 МВт. К 4 часам утра тепловая мощность реактора была снижена на 50\%, до 1600 МВт. В 14 часов система аварийного охлаждения реактора была отключена от контура циркуляции и начата подготовка энергоблока к проведению испытаний. Именно в это время раздался звонок из Киевэнерго, диспетчер попросил отсрочки выполнения программы испытаний хотя бы на 12 часов, т.к. в воскресные дни мощности киевских энергосетей не хватало для нормального режима их эксплуатации. Персонал энергоблока не обязан был выполнять такие вводные, не предусмотренные программой, однако пошли навстречу Киевэнерго. Блок продолжал работать на мощности 1600 МВт, а должен был - на 700 МВт. Это первое отклонение от программы испытаний.

В 23 ч 10 мин снижение мощности энергоблока было продолжено и в 00 ч 05 мин 26 апреля тепловая мощность реактора снижена до 720 МВт. В это время произошла смена оперативного персонала 4-го энергоблока. Испытаниями руководил заместитель главного инженера А. Дятлов. Испытания начались в 01 ч 23 мин 04 с. Начало испытаний. Начался выбег четырех ГЦН. Через 6 секунд была нажата кнопка МПА (максимальная проектная авария) специально смонтированная для имитации сигналами. Грубейшим нарушением регламента эксплуатации реактора персоналом явилось нахождение в этот момент в верх- нем положении 205 стержней, т.е. в активной зоне оставалось всего 6 стержней (по некоторым показаниям свидетелей аварии 18), что привело к мгновенной неуправляемой ядерной реакции с выделением колоссального количества энергии. Другими словами, произошел неконтролируемый разгон мощности, приведший к очень быстрому переводу теплоносителя в пар высокого давления. Этот пар, расширяясь, подтолкнул массивную 1000-тонную крышку реактора вверх. Крышка реактора была подброшена на высоту более 10 м, развернулась в воздухе и упала обратно ребром, раздавив верхнюю часть активной зоны. Этот паровой взрыв, разрушивший активную зону реактора, произошел в считанные секунды. В результате смесь паpa, обломков графитовой кладки, ядерного топлива, технологических каналов и других конструкционных элементов активной зоны реактора была выброшена наружу. «Первый взрыв», который был паровым, не являлся взрывом, как физическим явлением, а представлял собой процесс разрушения активной зоны реактора перегретым паром. В 01 ч 23 мин 40 с нажата кнопка А3-5 аварийной защиты реактора. Стержни аварийной защиты начали двигаться в активную зону. Но так как за 1 минуту до аварии ОЗР снизился до 6 стержней, то это привело при нажатии кнопки А3-5 к проявлению положительного выбега, т.е. к росту мощности реактора. В результате пароциркониевой реакции в считанные секунды образовалось огромное количество водорода. В работе [4] было показано, что «... в условиях аварии в активной зоне реактора 4-го блока только за счёт этой реакции в течение 3 с могло образоваться до $5000 \mathrm{~m}^{3}$ водорода. Вырвавшаяся масса водорода, перемешавшись с воздухом центрального зала, образовала детонационную воздушноводородную смесь, которая затем взорвалась. Именно этот взрыв, аналогичный взрыву «вакуумной бомбы», разнёс вдребезги крышу, центральный зал и другие помещения 4-го блока, были перебиты кабели электропитания» (см. рис. 4). 


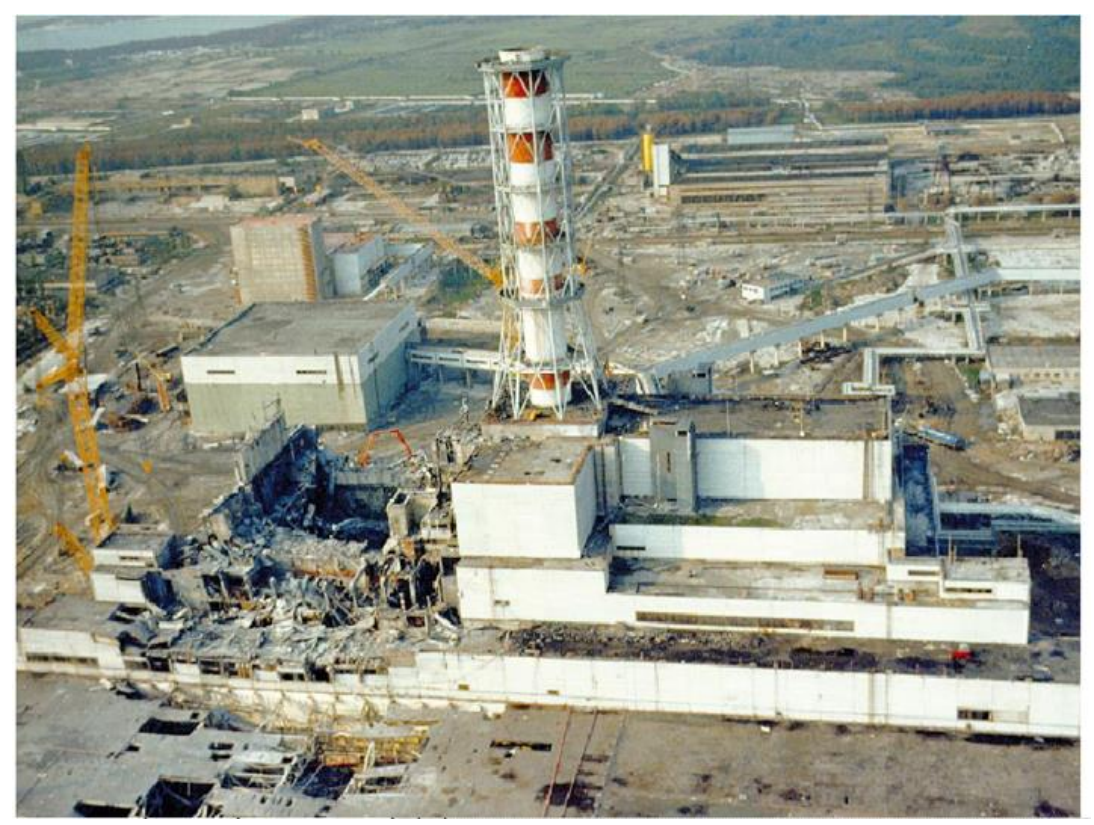

Рис. 4. Разрушенный 4-й энергоблок ЧАЭС

Fig. 4. The destroyed 4th power unit of the Chernobyl Nuclear Power Plant

Столб паро-газо-аэрозольной смеси, содержащей большое количество легких ПЯД, поднялся на высоту 1-2 км и начал распространяться по направлению розы ветров в северо-западном направлении, через территорию Белоруссии в сторону Скандинавских стран.

В реакторе температура поднялась до $3000^{\circ} \mathrm{C}$, он превратился в своеобразный вулкан, в подреакторных помещениях начался процесс образования лавообразных масс, содержащих топливосодержащие материалы, которые пошли по коридорам и коммуникациям энергоблока.

Уже 26 апреля 1986 г. была организована Правительственная комиссия по расследованию причин аварии на Чернобыльской АЭС во главе с заместителем председателя Совета Министров СССР Б.Е. Щербиной, которая в этот же день прибыла на место аварии [5]. От Академии наук СССР в комиссию был включен акад. В.А. Легасов, который на основании заключения Правительственной комиссии сделал доклад на конференции экспертов МАГАТЭ, посвященной анализу причин аварии на ЧАЭС и радиологическим последствиям катастрофы, состоявшейся 25-29 августа 1986 г. в Вене. По заключению Правительственной ко- миссии [6] катастрофа произошла из-за нейтронно-физических и конструктивных особенностей реактора РБМК-1000 и действий персонала, который совершил ряд ошибок и грубо нарушил правила эксплуатации реактора при проведении испытаний СОБ. При этом Государственная комиссия основную ответственность за аварию возложила на оперативный персонал и руководство ЧАЭС.

В информации об аварии на ЧАЭС, подготовленной членами Правительственной комиссии для МАГАТЭ, говорилось о следующих грубых нарушениях правил эксплуатации АЭС, совершённых её персоналом [6]:

- проведение эксперимента «любой ценой», несмотря на изменение состояния реактора;

- вывод из активной зоны реактора недопустимо большого количества стержней регулирования цепной ядерной реакции;

- вывод из работы исправных технологических защит, которые просто остановили бы реактор ещё до того, как он попал в опасный режим;

- замалчивание масштаба аварии в первые дни руководством ЧАЭС. 
В 1987 г. состоялся суд, на котором в качестве обвиняемых предстали руководители Чернобыльской АЭС: директор В. Брюхановым, главный инженер $\mathrm{H}$. Фомин, заместитель главного инженера А. Дятлов, а также начальник реакторного цеха А. Коваленко, начальник смены Б. Рогожкин и государственный инспектор Госатомтехнадзора СССР Ю. Лаушкин. Все они были признаны виновными и осуждены на разные сроки. Материалы дела и сведения об аварии засекретили.

МАГАТЭ создало свою консультативную группу, известную как Консультативный комитет по вопросам ядерной безопасности (INSAG; International Nuclear Safety Advisory Group), которая в своих выводах согласилась с заключением Правительственной комиссии СССР [7]. В докладе МАГАТЕ под названием INSAG-1 были указаны основные недостатки реактора РБМК-1000 в его исполнении по состоянию на 1986 г., к которым были отнесены:

- низкая скоростная эффективность системы управления и защиты реактора (ввод стержней управления и защиты в реактор производился за 18 секунд, в то время, как на реакторах других типов он составлял 2-4 секунды), что не позволяло системе управления и защиты справиться с быстропротекающими процессами;

- конструкция стержней управления и защиты, которая приводила к тому, что при определенных обстоятельствах аварийная защита не останавливала реактор, а вводила в него положительную реактивность и становилась инициатором разгона мощности реактора;

- недопустимо высокий паровой коэффициент реактивности, в результате чего, во-первых, в определенных режимах общий мощностной коэффициент реактивности реактора становился положительным и, во-вторых, снижение плотности теплоносителя в реакторе, независимо от причины, приводило к катастрофическому росту мощности;

- двугорбое по высоте поле энерговыделения, которое в совокупности с недостатками системы управления и защиты реактора создавало предпосылки для формирования в нижней половине реактора квазисамостоятельной активной зоны с недопустимо высокой скоростью роста мощности в случае срабатывания аварийной защиты реактора при малом оперативном запасе реактивности.

До чернобыльской аварии в $\mathrm{CCCP}$ планировалось введение в эксплуатацию и строительство около десятка реакторов РБМК, однако после аварии эти планы были свёрнуты. Так и не были введены в эксплуатацию 5-й и 6-й энергоблоки ЧАЭС, было остановлено строительство двух энергоблоков РБМК-1500 на Костромской АЭС.

В 1993 г. МАГАТЭ опубликовало дополнительный отчёт INSAG-7 [8], обновивший ту часть доклада INSAG-1, в которой основное внимание было уделено причинам аварии. В этом отчете, основанном на новых данных, полученных в результате моделирования аварии, основное внимание уделялось серьёзным проблемам в конструкции реактора. Многие выводы, сделанные в 1986 г. в INSAG-1, были признаны неверными и изменены. Согласно INSAG-7, наиболее вероятной причиной аварии являлись ошибки проекта и конструкции реактора, которые оказали основное влияние на ход аварии и её последствия. Согласно INSAG-7 основными факторами, внёсшими вклад в возникновение аварии, явились следующие [8]:

- реактор не соответствовал нормам безопасности и имел опасные конструктивные особенности;

- низкое качество регламента эксплуатации в части обеспечения безопасности;

- неэффективность режима регулирования и надзора за безопасностью в ядерной энергетике, общая недостаточность культуры безопасности в ядерных вопросах как на национальном, так и на местном уровне;

- отсутствовал эффективный обмен информацией по безопасности как между операторами, так и между операторами и проектировщиками, персонал не обладал достаточным пониманием особенностей станции, влияющих на безопасность; 
- персонал допустил ряд ошибок и нарушил существующие инструкции и программу испытаний.

Именно выводы этого доклада послужили основанием для остановки действующих реакторов РБМК, в частности, на ЧАЭС 2-й энергоблок был остановлен в 1991 г., 1-й - в 1996 г., 3-й - в декабре 2000 г.; два блока Ингалинской АЭС на северо-востоке Литвы, введенные в эксплуатацию в 1983 г., были остановлены в 2009 г.

Существовало много версий причин чернобыльской аварии, в том числе кавитация, террористические действия, сейсмическая активность и др. Однако основными оставались две причины конструкционные особенности реактора РБМК и человеческий фактор. Кроме того, как отмечается в Российском национальном докладе «25 лет чернобыльской аварии. Итоги и перспективы преодоления ее последствий в России» [5], самая крупная в истории мировой атомной энергетики авария стала возможна только в условиях наличия серьезных проблем в области управления и регулирования безопасности атомной энергетики в СССР.

Тем не менее, на основе анализа признаний главных участников аварийных событий через много лет после аварии становится очевидным, что, несмотря на ряд конструкционных недостатков реактора РБМК, они могли только способствовать аварии, но не спровоцировать её. В ряде научных публикаций предпочтение отдавалось версии, что взрыв реактора 4-го энергоблока произошел только по вине персонала $[9,10]$.

Реакторы РБМК сегодня. После обнародования причин аварии на ЧАЭС в обществе закрепилось мнение о том, что аварии, подобные Чернобыльской, возможны именно на реакторах РБМК. На волне всеобщей радиофобии активизировались различные движения «зеленых» и иных «правозащитников», требующих закрытия строящихся АЭС. Эти события совпали с развалом СССР. Руководства образовавшихся независимых государств, столкнувшиеся с большими социально-экономическими трудностями, возникшими с развалом некогда мощной страны, несмотря на устранение выявленных недостатков конструкции РБМК, регламента его эксплуатации, основываясь на выводах МАГАТЭ, принимали решение о прекращении строительства новых АЭС и остановке действующих реакторов РБМК.

По современным данным «Росатома» [11] после Чернобыльской катастрофы реакторы РБМК претерпели существенную реконструкцию с целью исключения даже гипотетической вероятности крупной аварии. Так, в реакторах стали использовать более обогащенное уранотопливо $\left(2,4 \%\right.$ по $\left.{ }^{235} \mathrm{U}\right)$, увеличили количество стержней, контролирующих цепную реакцию, до 70, а также внедрили современные диагностические системы.

В России по сей день эксплуатируется девять реакторов РБМК на трех атомных станциях: три реактора на Ленинградской, три на Смоленской и три на Курской АЭС.

По результатам компьютерного моделирования, проведенного госкорпорацией «Росатом», вероятность аварийных ситуаций на реакторах РБМК выявлена как крайне низкая (примерно 1 раз в 10 тыс. лет), что соответствует нормативам МАГАТЭ для эксплуатируемых сейчас в мире реакторов соответствующего поколения [11].

«Росатом» планирует полностью заменить реакторы РБМК-1000 новыми энергоблоками ВВЭР-1200 к 2035 г.

Радиоэкологические последствия аварии. По характеру протекания процессов разрушения 4-го блока и по масштабам последствий авария на ЧАЭС имела категорию запроектной и относилась к 7-му уровню (тяжелые аварии) по международной шкале ядерных событий INES. Катастрофически большие масштабы выброса (50 млн Ки) привели к загрязнению огромной территории бывшего СССР и других стран (миллионы гектаров) радионуклидами, значительная часть которых выпала в 30-километровой зоне.

В Российской федерации наибольшему радиационному загрязнению подверглись Брянская, Калужская, Орловская и Тульская области (рис. 5). 


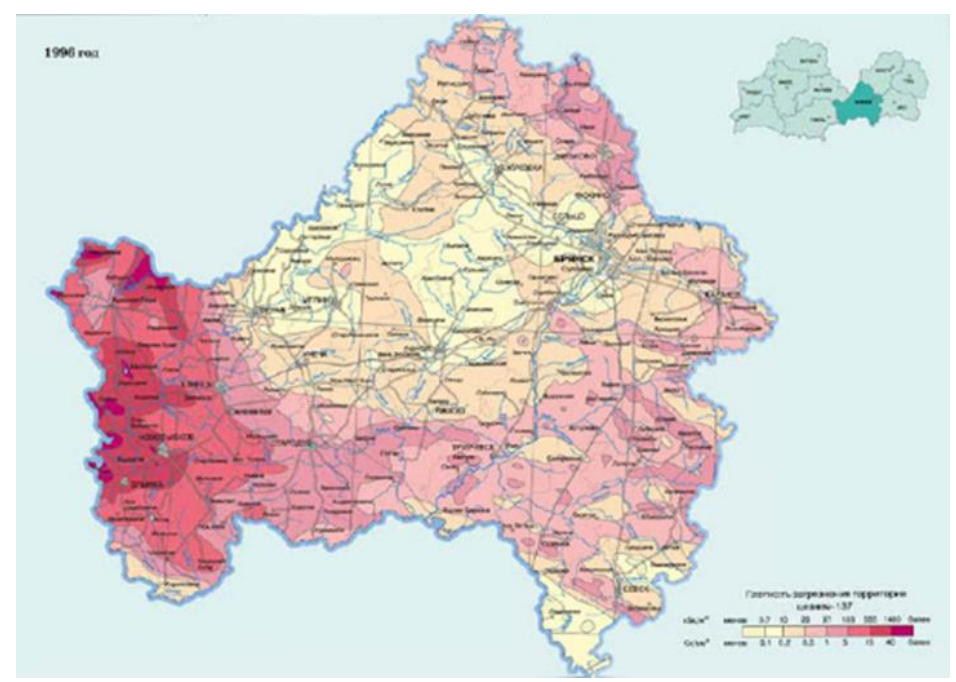

Рис. 5. Карта-схема загрязнения территории Брянской, Калужской, Орловской и Тульской областей цезием-137 Чернобыльского происхождения [12]

Fig. 5. Map-scheme of contamination of the territory of the Bryansk, Kaluga, Oryol and Tula regions with caesium-137 of Chernobyl origin [12]

На радиационно-загрязненных территориях постоянно ведется радиоэкологический мониторинг нахождения радионуклидов в объектах окружающей среды, их миграции в пищевых цепях и нахождения в продуктах питания.

Цезий-137 и стронций-90, являясь основными дозоопределяющими ПЯД урана, в больших количествах попавшие в окружающую среду, будут активными ещё более 250 лет. По пищевым цепочкам они попадают в организмы человека и животных. К радиоэкологическим особенностям чернобыльской аварии следует также отнести следующие:

a) начавшийся в результате взрыва и резкого повышения температуры пожар графитовой кладки, поддерживаемый большой энергией, выделявшейся при распаде радионуклидов, привел к длительному выходу радиоактивности в атмосферу в форме струи, которая непрерывно меняла свое исходное направление, следуя направлению ветра. Интенсивный выброс в форме струи наблюдался около 10 суток, и радиоактивное облако, распространяясь в соответствии с розой ветров, меняло свое направление несколько раз: 26.04 на северо-запад; 27.04 - на запад; 27.04-28.04 - на восток; 29.04-01.05 - восточно-южное направление; 02.05-03.05 - южное; 04.05-06.05 - юго-западное. Метеоусловия, обуслов- ленные изменением направления ветра и осадками, стали причиной пятнистого характера загрязнения территории, неравномерности выпадений по территории в макро-, мезо- и микромасштабах по физико-химическим формам, радионуклидному составу и уровням;

б) сложный характер аварии, продолжительное время интенсивных выбросов, разнообразие форм и состава выпадений при изменении атмосферных условий во время аварии. Значительная часть радионуклидов находилась в составе малорастворимой топливной матрицы - «горячие частицы», которые в окружающей среде подвергаются абиотическим и биотическим процессам трансформации, постепенному переходу радиоактивных компонентов в растворимые формы и их миграции в объектах окружающей среды;

в) вывод из народнохозяйственной деятельности больших территорий (около 3 тыс. км²) и превращение их в Зону отчуждения (3О). В настоящее время в 30 , на которой отсутствует антропогенное воздействие на природу, происходят автореабилитационные процессы;

г) в первый период после аварии основным биологически значимым радионуклидом, попавшим в окружающую среду во время аварии, являлся йод- $131 \mathrm{c}$ периодом полураспада $\mathrm{T}_{1 / 2}=8,3$ суток. 
В последующие более отдаленные периоды основной вклад в дозовую нагрузку при внутреннем облучении за счет попадания в организм по пищевым цепочкам вносят самые долгоживущие ПЯД - стронций-90 и цезий-137 с периодом полураспада около 30 лет, т.е. они будут оставаться активными ещё более 250 лет. Оба эти радионуклида биологически значимы, так как ${ }^{90} \mathrm{Sr}$ является аналогом кальция, ${ }^{137} \mathrm{Cs}$ - аналог калия. Поэтому они представляют радиацион- ную опасность для человека и животных;

д) ещё одна из актуальных радиоэкологических проблем - проблема плутония чернобыльского происхождения [13]. Являясь тяжелым ТУЭ, он выпал, в основном, вблизи реактора. Однако определенная его часть достигла расстояний до 100 км, поэтому загрязнению плутонием подверглась Брянская область, расположенная ближе всего к границе с Украиной (рис. 6).

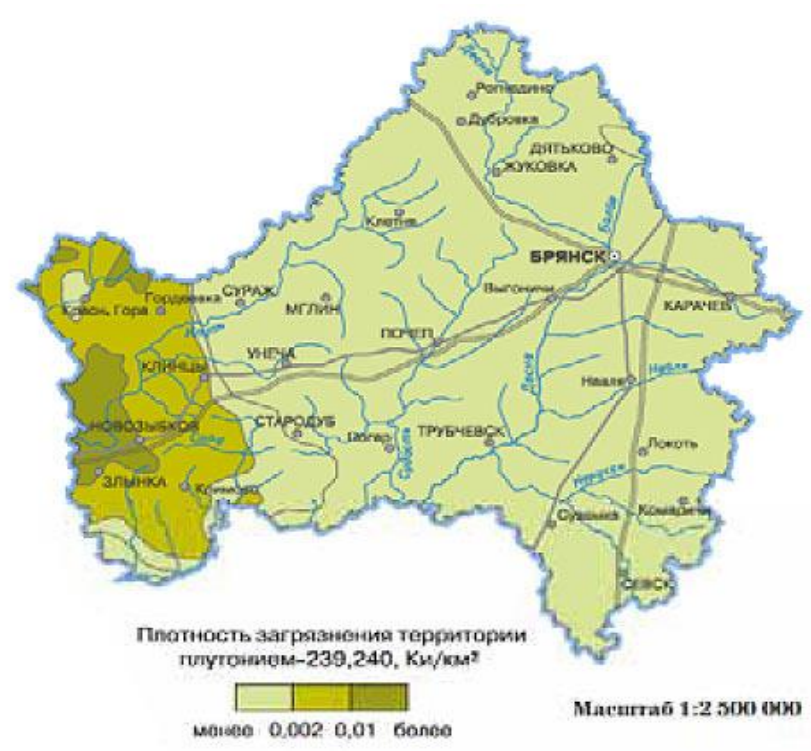

Рис. 6. Загрязнение Брянской области плутонием Чернобыльского происхождения [12]

Fig. 6. Contamination of the Bryansk region with plutonium of Chernobyl origin [12]

Из всех изотопов плутония, попавших в окружающую среду в результате аварии, наибольшей активностью обладал ${ }^{241} \mathrm{Pu}, \beta$-излучатель с периодом полураспада $\mathrm{T}_{1 / 2}=14,4$ года. $\mathrm{K}$ сегодняшнему дню ${ }^{241} \mathrm{Pu}$ претерпел уже 2,5 периода распада. Однако при бета-распаде плутония-241, он превращается в более подвижный в экосистемах и более опасный $\alpha$-излучатель - америций-241 с периодом полураспада $\mathrm{T}_{1 / 2}=432,6$ года. Поэтому процесс естественного уменьшения ${ }^{241} \mathrm{Pu}$ ведет к загрязнению экосистем ${ }^{241} \mathrm{Am}$, который будет оставаться активным около 4300 лет.

Выводы. 1. Основными причинами аварии в Информации об аварии на Чернобыльской АЭС и ее последствиях, подготовленной для МАГАТЭ членами Правительственной комиссии по расследовании причин аварии, а также в докла- де Международной консультативной группы по ядерной безопасности INSAG-1 в 1986 г. указаны конструктивные особенности реактора РБМК-1000 и действия персонала, который совершил ряд ошибок и грубо нарушил правила эксплуатации реактора при проведении испытаний СОБ.

2. В 1993 г. МАГАТЭ опубликовало дополнение к INSAG-1 Международная консультативная группа по ядерной безопасности опубликовала - Доклад Международной консультативной группы по ядерной безопасности - INSAG-7, в котором многие выводы, сделанные в 1986 г. были признаны неверными и изменены. Согласно INSAG-7, наиболее вероятной причиной аварии являлись ошибки проекта и конструкции реактора.

3. На основе анализа признаний главных участников аварийных событий 
через много лет после аварии становится очевидным, что, несмотря на ряд конструкционных недостатков реактора РБМК, они могли только способствовать аварии, но не спровоцировать её. Основной причиной аварии на ЧАЭС стал человеческий фактор - грубые ошибки персонала.

4. После существенной реконструкции реакторов РБМК в России в настоящее время эксплуатируется девять таких реакторов на трех АЭС - Ленинградской, Курской и Смоленской.

5. Ликвидация радиоэкологических последствий аварии продолжается по сей день. На радиационно-загрязненных территориях постоянно ведется радиоэкологический мониторинг нахождения и миграции радионуклидов чернобыльского происхождения в объектах окружающей среды, в пищевых цепях и их поступления в продукты питания.

6. Главный урок, извлеченный из аварии и её последствий, заключается в необходимости внимательного отношения к вопросам безопасного использования достижений научно-технического прогресса, в недопущении техногенных катастроф и аварий.

\section{СПИСОК ЛИТЕРАТУРЫ}

1. Экологические последствия аварии на Чернобыльской АЭС и их преодоление. Двадцатилетний опыт: доклад экспертной группы «Экология» Чернобыльского форума. Вена: МАГАТЭ, 2008. $180 \mathrm{c}$.

2. Атомная энергетика после аварии - по материалам ИБРАЭ РАН http://www.ibrae.ac.ru/russian/chernobyl3d/society/III_1_3.htm (дата обращения: 14.04.2021).

3. Российский национальный доклад «30 лет чернобыльской аварии. Итоги и перспективы преодоления ее последствий в России 1986-2016» / под общей ред. В.А. Пучкова и Л.А. Большова. М., 2016. 202 c.

4. Пазухин Э.М. Взрыв водородновоздушной смеси как возможная причина разрушения центрального зала 4-го блока Чернобыльской АЭС во время аварии 26 апреля 1986 г. // Радиохимия.
1997. Т. 39. Вып. 4. С. 379-384.

5. Российский национальный доклад «25 лет чернобыльской аварии. Итоги и перспективы преодоления ее последствий в России 1986-2011»/ под общей ред. С.К. Шойгу, Л.А. Большова. М., 2011. 160 c.

6. Информащия об аварии на Чернобыльской АЭС и ее последствиях, подготовленная для МАГАТЭ // Атомная энергия. 1986. Т. 61. Вып. 5. С. 301-320.

7. Итоговый доклад о совещании по рассмотрению причин и последствий аварии в Чернобыле. Доклад Международной консультативной группы по ядерной безопасности - МАГАТЭ, Вена. 1988. $114 \mathrm{c}$.

8. Чернобыльская авария: дополнение к INSAG-1: Доклад Международной консультативной группы по ядерной безопасности. Вена: МАГАТЭ, 1993. (Серия изданий по безопасности; № 75INSAG-7).

9. Горбачев Б.И. Причины Чернобыльской аварии: окончательный выбор между двумя версиями // Проблеми Чорнобиля. 2002. Вип. 10. Ч. 1. С. 121-146

10. Горбачев Б.И. Новая хронология аварии на 4-м блоке Чернобыльской АЭС // Проблеми безпеки атомних електростанцій і Чорнобиля. 2005. Вип. 2. С. 128-132.

11. В тени Чернобыля: почему в России продолжают использовать старые реакторы. https://www.bbc.com/russian/ features-48872901

12. Атлас современных и прогнозных аспектов последствий аварии на Чернобыльской АЭС на пострадавших территориях России и Беларуси (АСПА Россия-Беларусь) / под. ред. Ю.А. Израэля и И.М. Богдевича. Москва-Минск: Фонд «Инфосфера» - НИА-Природа, 2009. $140 \mathrm{c}$.

13. Лукина Л.И., Моисеев Д.В. и др. Экологические проблемы плутония чернобыльского происхождения // Экологическая, промышленная и энергетическая безопасность - 2018: сб. статей по материалам междунар. науч.-практ. конф. (24-27 сентября 2018 г.) / под ред. Л.И. Лукиной, Н.А. Бежина, Н.В. Ляминой. Севастополь: СевГУ, 2018. С. 731-735. 


\section{LESSONS FROM CHERNOBYL}

\section{L.I. Lukina, D.V. Moiseev}

Sevastopol State University, RF, Sevastopol, Universitetskaya St., 33

The article analyzes the causes of the accident at the Chernobyl nuclear power station on April 26, 1986. The authors believe that the 1986 accident at the 4th power unit resulted from extremely unlikely coincidence of circumstances. Both the design features of the RBMK reactor and the gross violations of its operation regulations by the personnel were the main contributing factors to the disaster development. The main lesson learned from the accident and its consequences, the elimination of which is still continuing to date, is the need for careful attitude to issues of safe use of the achievements of scientific and technological progress in such critical infrastructure facilities as nuclear power plants.

Keywords: radiation accident, Chernobyl NPP, RBMK reactor, radiation pollution, causes of the accident, consequences of the accident

\section{REFERENCES}

1. Ekologicheskie posledstviia avarii na Chernobylskoi AES i ikh preodolenie, Dvadtcatiletnii opyt, Doklad ekspertnoi gruppy "Ekologiia” Chernobylskogo foruma, Vena: MAGATE, 2008, 180 p.

2. Atomnaia energetika posle avarii - po materialam IBRAE RAN http://www.ibrae.ac.ru/russian/chernobyl-3d/society/III_1_3.htm (data obrashcheniia: 14.04.2021).

3. Puchkov V.A. and Bolshov L.A. Rossiiskii natcionalnyi doklad "30 let chernobylskoi avarii. Itogi i perspektivy preodoleniia ee posledstvii v Rossii 1986-2016”, Moscow, 2016, 202 p.

4. Pazukhin E.M. Vzryv vodorodno-vozdushnoi smesi kak vozmozhnaia prichina razrusheniia tcentralnogo zala 4-go bloka Chernobylskoi AES vo vremia avarii 26 aprelia $1986 \mathrm{~g}$. (The explosion of a hydrogen-air mixture as a possible cause of the destruction of the central hall of the 4th unit of the Chernobyl nuclear power plant during the accident on April 26, 1986.). Radiokhimiia, 1997, Vol. 39, No. 4, pp. 379-384.

5. Shoigu S.K. and Bolshov L.A. Rossiiskii natcionalnyi doklad "25 let chernobylskoi avarii. Itogi i perspektivy preodoleniia ee posledstvii v Rossii 1986-2011" (25 years of the Chernobyl accident. Results and prospects of overcoming its consequences in Russia 1986-2011) Moscow, 2011, 160 p.

6. Informatciia ob avarii na Chernobylskoi AES i ee posledstviiakh, podgotovlennaia dlia MAGATE (Information about the accident at the Chernobyl nuclear power plant and its consequences, prepared for the IAEA ) Atomnaia energiia. 1986. Vol. 61, No. 5, pp. 301-320.

7. Itogovyi doklad o soveshchanii po rassmotreniiu prichin i posledstvii avarii v Chernobyle (Final report on the meeting to consider the causes and consequences of the Chernobyl accident) Doklad Mezhdunarodnoi konsultativnoi gruppy po iadernoi bezopasnosti-MAGATE, Vena, 1988, $114 \mathrm{p}$.

8. Chernobylskaia avariia: dopolnenie k INSAG-1 (Chernobyl accident: addition to INSAG-1). Doklad Mezhdunarodnoi konsultativnoi gruppy po iadernoi bezopasnosti, Vena: MAGATE, 1993. (Seriia izdanii po bezopasnosti; No 75-INSAG-7).

9. Gorbachev B.I. Prichiny Chernobylskoi avarii: okonchatelnyi vybor mezhdu dvumia versiiami (Causes of the Chernobyl accident: the final choice between the two versions) Problemi Chornobilia, 2002, No 10, Ch. 1, pp. 121-146.

10. Gorbachev B.I. Novaia khronologiia avarii na 4-m bloke Chernobylskoi AES (New chronology of the accident at the 4th unit of the Chernobyl nuclear power plant) Problemi bezpeki atomnikh elektrostantcii i Chornobilia, 2005, No 2, pp. 128-132.

11. V teni Chernobylia: pochemu v Rossii prodolzhaiut ispolzovat starye reaktory (In the shadow of Chernobyl: why old reactors continue to be used in Russia.). https://www.bbc.com/russian/ features48872901

12.Izrael Iu.A. and Bogdevich I.M. Atlas sovremennykh i prognoznykh aspektov posledstvii avarii na Chernobylskoi AES na postradavshikh territoriiakh Rossii i Belarusi (ASPA Rossiia-Belarus) (Atlas of modern and possible consequences of the accident at the Chernobyl nuclear power plant in the affected territories of Russia and Belarus (ASPA Russia-Belarus)) Moscow-Minsk, Fond "Infosfera" NIA-Priroda, 2009, $140 \mathrm{p}$.

13. Lukina L.I., Moiseev D.V. et al. Ekologicheskie problemy plutoniia chernobylskogo proiskhozhdeniia (Environmental problems of plutonium of Chernobyl origin, Environmental, Industrial and Energy Security 2018) Ekologicheskaia, promyshlennaia i energeticheskaia bezopasnost 2018, cb. statei po materialam mezhdunar. nauch.-prakt. konf. (24-27 sentiabria 2018) Sevastopol, SevGU, 2018, pp. 731-735. 